\title{
Chapter 21 \\ Exploring Challenges and Opportunities of Life Cycle Management in the Electricity Sector
}

\author{
Miguel Fernandez Astudillo, Karin Treyer, Christian Bauer, \\ and Mourad Ben Amor
}

\begin{abstract}
Electricity supply is often cited as a significant hot spot in life cycle assessment results, and consequently in life cycle management results. Despite its importance, however, practitioners continue to overuse generic LCI data and different simplified methodologies regarding electricity supply modeling. Such simplifications and inconsistencies can result in difficulties, e.g. to compare the findings of various studies. This chapter is intended to highlight issues on electricity supply modeling, methodological choices and data set selections. Attributional and consequential perspectives as well as systemic aspects of the electricity sector are also reflected. Finally, key challenges and opportunities are summarized and suggestions on how to deal with such problems are provided when possible.
\end{abstract}

Keywords Energy policy • Electricity supply - Modeling choices $\bullet$ Life cycle inventory data $\bullet$ Life cycle assessment $\bullet$ Life cycle management

\section{Introduction}

Life cycle management (LCM) aims to minimize the environmental and socio-economic burdens associated with a product or product portfolio throughout its entire life cycle and value chain (Remmen et al. 2007). From an environmental perspective, electricity is a major consideration in many life cycle assessment (LCA) studies. Indeed, electricity supply is often highlighted as a significant hot

\footnotetext{
M.F. Astudillo • M.B. Amor $(\bowtie)$

Department of Civil Engineering, Université de Sherbrooke,

J1K 2R1 Sherbrooke, QC, Canada

e-mail: ben.amor@usherbrooke.ca

K. Treyer $\bullet$ C. Bauer

Laboratory for Energy Systems Analysis, Paul Scherrer Institut (PSI),

5232 Villigen, Switzerland 
spot in LCA results for a majority of product life cycles (Curran et al. 2005; Treyer and Bauer 2013). It has also been shown, from the LCA perspective, that electricity sector as such is an important originator of environmental burdens worldwide and that energy policies can result in burden-shifting (Laurent and Espinosa 2015). As LCAs are being conducted frequently, it is key that suitable life cycle inventory (LCI) data become in general more readily available (Soimakallio et al. 2011).

This book chapter aims to highlight issues on electricity supply modeling, methodological choices and data set selections. Attributional and consequential perspectives as well as systemic aspects of the electricity sector are also reflected. Finally, this chapter summarizes the key challenges and opportunities and provides suggestions on how to deal with such problems.

\section{Identifying the Issues: Major Methodological Challenges}

\subsection{Data Issues: Generating Electricity Life Cycle Inventory Datasets}

According to ISO 14044, electricity inventories shall take into account electricity mixes, fuel efficiencies, as well as transmission and distribution losses. Given the heterogeneity of electricity LCI data, representativeness is an important aspect when conducting an LCA. Referring to ISO 14044 (ISO 14044: 2006), data representativeness is the qualitative assessment of the degree to which the data set reflects the true population of interest for a specific application: geographical coverage, timerelated coverage, and technology coverage. Other quality indicators are such as completeness, consistency and uncertainty are also addressed. Aspects covering special challenges in the electricity sector are highlighted in the following sections.

\subsubsection{Geographic Coverage}

The geographical coverage is the geographical area from which data for unit processes should be collected to satisfy the goal of the study. In the context of electricity process, LCA practitioner can face two main challenges: the first one refers to the situation where no regionalized electricity data is available (Sect. 2.1.1.1) and the second one refers to the grid delimitation (Sect. 2.1.1.2).

\subsubsection{Extending the Geographical Coverage: Improving Production Data Accuracy}

Regionalization of inventory data is recognized as an important need to increase the accuracy of LCA results, even if it is disputed down to which level the regionalization should go. Recent efforts have been undertaken to increase the 
geographical scope of inventory data and using country-specific statistics. The life cycle inventory database ecoinvent version 3 covers nearly $85 \%$ of global electricity production in 2008 (Treyer and Bauer 2013) with country (or even region-specific) LCI data showing substantial differences in LCI data between specific countries and regions.

Despite the geographical coverage increase, gaps in LCI data keep existing and are in general more pronounced in non-OECD countries, where often extrapolations are unavoidable, increasing uncertainty (Treyer and Bauer 2013; Schmidt et al. 2011; Laurent and Espinosa 2015).

\subsubsection{Grid Mix Boundaries: From Production Mixes to Supply Mixes}

Once available in the grid, it is not possible to know where the electricity is coming from (Dones et al. 1998; Itten et al. 2014; Weber et al. 2010). This tracking issue becomes even more challenging as electricity grids are increasingly getting interconnected, and hence makes selecting a grid mix boundary a complicated task for the practitioner.

The common approach is to use national electricity mixes and accounting for imports from the neighboring jurisdictions. The underlying justification is that neighboring countries have either physical connections or administrative contracts to trade (Treyer and Bauer 2014). However, the boundaries selection is to some extent arbitrary and raises equity issues. As an example, if we take the NorthAmerican electricity grid, different resolutions are available: national, interconnect, Jurisdiction-average production and consumption mixes (US countries, Canadian provinces, etc.), ISO/RTO, EPA's eGrid subregions, and EIA region (Weber et al. 2010).

On top of that, congestion can effectively limit electricity transmission within a national boundary (an administrative barrier), which even makes the common approach selection (i.e. using the national energy mixes) unrealistic. A recent study developed an approach creating clusters of data according to the congestion status and its location within the Ontario (Canada) grid-mix. As an example, the avoided greenhouse gas emissions varied, for uncongested (i.e. using as a common approach selection the production energy mix: Ontario mix) and congested hours, between 280 and $390 \mathrm{~kg} / \mathrm{MWh}$. Even if these empirical estimates cannot be generalized to other contexts, the study underscored the importance of congestion in defining the grid mix boundary (Amor et al. 2014a).

\subsubsection{Temporal Aspects of Electricity}

Our capacity to store electricity is very limited, and in practice demand is dynamically (hour by hour) matched with a range of production technologies. Obtaining past yearly-averaged country supply mixes to be used in attributional LCA (ALCA) is relatively straightforward by using national statics. Typically organizations such 
as International Energy Agency (IEA) provide these data, even if the often-rough categorization of fuel and power plant categories in the statistics calls for assumptions and extrapolations increasing uncertainties. However, predicting and capturing changes in time of the electricity sector - being relevant in consequential LCA (CLCA) - is a challenging task, for both temporal scopes: short-term and long-term horizon.

\subsubsection{Short-Term}

In countries with de-regulated energy sectors, an independent system operator coordinates most of the markets by using price based dispatch systems. Price bids from generators, defining the supply curve would be ideal for analyzing the short-term variation of power plant production following different resolution: from hourly to annually and then be able to consider intermittency of renewable energy, intertemporal arbitrage, spinning and non-spinning reserves or ramp-rate limitations of producers.

However, price bids are not always publicly available. In the absence of such data, a procedure for integrating the short-term time variations of technologies is missing. Such a procedure could play an important role in increasing the robustness of LCA studies and refining their environmental impact estimates. Additionally, not all electricity markets have the same extent of de-regulation. As an example, leading players like China, the world largest consumer of electricity, still relies on a considerably more complex multi-level dispatch hierarchy partially based on generator output planning (Kahrl and Wang 2014).

\subsubsection{Long-Term}

In the long-term, additional capacity would need to be installed to cover increases in demand. Changes in the electricity sector depend on political, environmental and economic considerations that are substantially uncertain and country specific.

Different techniques are available to estimate prospective electricity mix. These techniques are useful from the average ALCA perspective and also from the CLCA perspective.

Future supply mixes can be estimated from national forecast, such as IEA annual energy outlook (e.g. Hertwich et al. 2015). In the absence of such available data, specific models (e.g. partial equilibrium models) can be used to estimate future average supply mixes: LEAP, TIMES, (see Pfenninger et al. 2014 for a review). CLCA often follows the step-wise procedure presented by Ekvall and Weidema (2004) and updated in Weidema et al. (2009) to identify marginal technologies but its application to the electricity sector is not yet satisfactory (Treyer and Bauer 
2014). Marginal changes in the electricity sector are likely to affect a range of technologies (Pehnt et al. 2008; Mathiesen et al. 2009) and it is not straightforward task to consistently identify them with a heuristic approach (Zamagni et al. 2012; Earles and Halog 2011; Menten et al. 2015). Energy system models such as TIMES or LEAP can help to overcome such difficulties.

\subsubsection{Technology Coverage}

The main challenges in technology data coverage concerns currently used technologies and those, which will be installed in the future and are not yet commercially available (e.g. on a pilot plant level).

\subsubsection{Actual Technologies}

There is a wide variation among generation stations in terms of emissions and inputs per unit generation across and even within fuel types. Such variation becomes even more challenging with the differences among statistics sources (e.g. Eurostat and EIA) treating the same technology using a given fuel type at a given geographic location (e.g. jurisdiction). Specification of the time frame of LCI data can also be challenging: statistic sources often refer to different years and the availability of up-to-date data is not always given, depending on the type of environmental exchanges. In addition to that, there is considerable uncertainty over certain emission factors, even for mature technologies, such as hydropower or coal (Hertwich 2013; Henriksson et al. 2014). Moreover, not only LCI data for power plants as such can substantially vary, also specific fuel supply as well as infrastructure manufacturing chains can have important effects on LCA results (Bouman et al. 2015; Yue et al. 2014).

\subsubsection{Prospective Technologies}

Prospective LCA studies often rely on LCI data of current electricity generation, even if technology performance of current power generation chains is likely to improve in the future and new technologies will emerge (IEA 2014). Modeling how technology performance will change over time is particularly difficult for nascent technologies (Curran et al. 2005) such as organic photovoltaic panels or carbon capture and storage (Volkart et al. 2013). Moreover, disruptive technologies can bring improvements in efficiency, but also have implied changes in infrastructure and user behavior, which are more difficult to predict (Miller and Keoleian 2015). 


\subsection{User Perspective: Using Electricity Life Cycle Inventory Data}

LCA practitioners, especially in industry, frequently rely on generic LCI data for electricity generation and supply from commercial LCA background databases such as ecoinvent, ${ }^{1} \mathrm{GaBi}^{2}{ }^{2}$ or ELCD ${ }^{3}$ in their daily LCA business. Therefore, the quality of these data is often crucial for the quality of LCA applications (e.g. certification, Eco-design, decision making) and users are confronted with the data issues discussed above.

Usually, use of generic electricity from the grid, i.e. electricity supply mixes, and from the generic electricity market, respectively, is sufficient in the industrial LCM context, if companies do not have own power plants or specific contracts for power supply.

However, today's industrial value chains are for many global products, i.e. industrial production, manufacturing, sales and research activities are distributed around the globe. In such cases, LCI data for electricity supply in different countries need to be used for LCM applications.

Background electricity LCI data need to represent actual local or regional/ national power supply as close as possible in order to be useful for LCA practitioners. "As close as possible" means that the background data need to represent specific supply regions and markets, respectively, and need to be up-to-date in terms of technology market shares, technology performance as well as fuel and infrastructure supply chains. They also need to be available in a modifiable way on the unit process level in order to allow users to adapt the data to their specific needs in case they have more specific information concerning their electricity supply. This requirement calls for a comprehensive and transparent documentation on the unit process level as well.

Today, most LCAs in the LCM context are attributional (Zamagni et al. 2012; Masanet et al. 2013). However, taking into account goal and scope and changeoriented questions to be answered by LCA carried out in industry, consequential LCA should be performed more frequently. Ideally, such CLCA will be based on consequential background data as well, also for electricity supply. Unfortunately, the availability of consequential background data is currently limited to the ecoinvent database and even these data need to be used cautiously (Treyer and Bauer 2014).

Change-oriented and prospective LCA also calls for background data taking into account technology development, i.e. representing future technologies and economies. However, such "future background data" are almost unavailable, at least in a consistently implemented way. The only known attempt to create consistent LCI data for future electricity production was carried out in the European research project "NEEDS" and LCI data are available online. ${ }^{4}$

\footnotetext{
${ }^{1}$ www.ecoinvent.org

${ }^{2}$ http://www.gabi-software.com/international/databases/gabi-databases/

${ }^{3}$ http://eplca.jrc.ec.europa.eu/ELCD3/

${ }^{4}$ http://www.needs-project.org/needswebdb/search.php
} 


\section{Key Opportunities}

\subsection{Opportunities: The Research Perspective}

\subsubsection{Integration with Other Modeling Methods}

\subsubsection{Modeling Electricity Mixes}

The environmental assessment of different strategies and policies in the energy and electricity sector, respectively, calls for integration of energy and electricity scenario modeling and LCA. Such integration needs to take into account systemic aspects, e.g. continuously matching power demand and supply, and should be performed with a relatively high temporal resolution (Messagie et al. 2014). Existing attempts to model electricity sector dynamics and their effect on electricity mixes have relied on standard economic models, both in the long-term (Pehnt et al. 2008; Lund et al. 2010) and short-term (Amor et al. 2014b). Electricity spot markets have been modeled assuming partial equilibrium conditions (i.e. ignoring feedback loops with markets outside the evaluated system). Electricity mixes were calculated minimizing cost, reproducing the bid-based clearance of electricity markets.

These approaches allow the integration of short-term dynamics characteristic of the electricity sector in long-term projections. The effect of public policies, such as taxes or subsidies can be included in the analysis with the help of life cycle costing. The scenarios can be, however, highly sensitive to uncertainties (Menten et al. 2015), and a thoughtful scenario analysis and a clear account of the limitations of studies is therefore needed. The integration of economic models increases substantially the number of variables, especially if general equilibrium models are used. In this case uncertainty assessments start to be computationally challenging and new approaches would need to be explored (Dandres et al. 2014). Initiatives such as the ENTSO-E ${ }^{5}$ transparency platform of the pan-European electricity market can be very helpful to reduce uncertainty and effectively integrate short-term dynamics. Finally, Frischknecht and Stucki (2010) have proposed the so-called decisional approach and demonstrated it for electricity supply in industry, but this approach has not received wide attention and deserves more studies.

\subsubsection{Filling Data Gaps}

In the absence of specific data from facilities, statistic techniques can be used to estimate emission factors and associated uncertainties. Using the regression approach, emissions factors can be estimated from available data such as plant age, fuel type and country gross domestic product (see e.g. Steinmann et al.

\footnotetext{
${ }^{5} \mathrm{https}: / /$ transparency.entsoe.eu/
} 
2014b). Statistical interpolation methods such as kriging have also been tested and appear to be superior to regression analysis (Moreau et al. 2012) but their application in LCI need to be extended. The same observation remains regarding the effects of technological change to be accounted for in prospective LCA. Experience curves have been used to predict improvements in efficiency and effect of investment (Sandén and Karlström 2007) but more work is needed on the treatment of related uncertainties (Yeh and Rubin 2012; Miller and Keoleian 2015).

\subsubsection{Uncertainty Management}

Recent advances in the uncertainty management can be used to improve the models of the electricity sector. At the inventory level, data inaccuracy and lack of representative data are typically addressed using the semi-quantitative approach of the pedigree matrix, assuming log-normal distributions. New advances in LCI implementation now allow to model parameter uncertainty with different types of probability distributions, allowing the modeler to use the distribution that best fits the data (Muller et al. 2014).

In addition, it is recommended to distinguish between uncertainty and variability, as just uncertainty can be reduced with better data. Recent studies suggest that the spread in emissions of power plants can be dominated by uncertainty (Henriksson et al. 2014) or variability (Steinmann et al. 2014a) depending on the region under study. To support the modeling, novel methodological developments propose ways of tackling this issue (Steinmann et al. 2014a).

\subsection{Opportunities: The User Perspective}

\subsubsection{Greater Use of Consequential Analysis}

Most LCAs performed to date on electric power and systems can be classified as attributional. However, beyond the coming methodological improvement, ALCAs are not designed to assess the total environmental implications (i.e. consequences) of decisions. Alternatively, CLCAs are particularly useful for estimating the energy and emissions implications of policies such as a Renewable Portfolio Standard or those of policies that encourage carbon taxes (Amor et al. 2010; Masanet et al. 2013). Thus, increasing CLCA use help in understanding and improving the effects of a given energy policy.

There is an urgent need to introduce large improvements in the electricity sector, which will entail major economic and environmental consequences. The analysis of future scenarios will especially suit CLCA, which should receive more attention to overcome the challenges and profit from the opportunities outlined in this chapter. 


\subsubsection{Best Practices}

In cases where it is important to accurately estimate the environmental impacts associated with electricity use with high temporal resolution, using a methodology where the electricity dynamics is considered (as developed by Amor et al. 2014b) is recommended. Such approaches are particularly relevant in assessing the implication of choosing different electricity supply modeling approaches during decisionmaking, e.g. in estimating the avoided environmental impacts as a consequence of renewable distributed generation.

In other cases, one must keep in mind the often-limited resources of LCA practitioners; generating specific LCI data for electricity supply at a high level of detail can be arduous, and often relying on generic background data from databases can be sufficient. However, these generic data should be adapted through modification of key parameters in order to represent specific electricity supply more closely.

In any case, knowing the implications associated with electricity supply modeling choices, it is highly recommended that practitioners exercise caution and sensitivity analyses should be systematically conducted using different electricity supply scenarios in order to take into account the complexity of electricity systems.

Finally, interpretation of LCA results of electricity generation technologies deserves attention, especially if used for decision support. Often, results show substantial variations without transparently documented and easily traceable underlying reasons. In this context, the harmonization approach by NREL (Brandão et al. 2012) should be considered.

\section{Conclusions}

This chapter summarizes key challenges and opportunities of LCM in the electricity sector, with focus at inventory level. Despite the advances, the challenges are numerous and span from gaps in geographical and technological coverage, uncertainties over emission factors, to complexities on the identification of marginal technologies.

There are many opportunities to improve the inventories that are being currently explored and some are described here: Economic models are being used to identify marginal technologies and assess the effect of policies, statistical techniques such as regression analysis are useful to fill inventory data gaps and experience curves can be used to assess novel technologies. As any methodological development, one should however, be very clear about their limitations, provide transparent documentation and uncertainty estimates together with the results.

Some of these developments are already available for practitioners, including consequential inventories, greater capabilities in uncertainty modeling and parameterized datasets. Other developments are not yet available in databases and would require that data providers take methodological decisions to maintain consistent inventories. These decisions could include questions where interpretation of ISO 
standards are less clear such as how to foresee marginal technologies, which data sources are more reliable or how to deal with the traceability of electricity. Dialogue between users and providers is therefore suggested to overcome methodological differences and help to build a sustainable electric sector.

Open Access This chapter is distributed under the terms of the Creative Commons Attribution Noncommercial License, which permits any noncommercial use, distribution, and reproduction in any medium, provided the original author(s) and source are credited.

\section{References}

Amor MB, Lesage P, Pineau P-O, Samson R (2010) Can distributed generation offer substantial benefits in a Northeastern American context? A case study of small-scale renewable technologies using a life cycle methodology. Renew Sustain Energy Rev 14:2885-2895

Amor MB, Billette de Villemeur E, Pellat M, Pineau P-O (2014a) Influence of wind power on hourly electricity prices and GHG (greenhouse gas) emissions: evidence that congestion matters from Ontario zonal data. Energy 66:458-469

Amor MB, Gaudreault C, Pineau P-O, Samson R (2014b) Implications of integrating electricity supply dynamics into life cycle assessment: a case study of renewable distributed generation. Renew Energy 69:410-419

Bouman EA, Ramirez A, Hertwich E (2015) Multiregional environmental comparison of fossil fuel power generation - assessment of the contribution of fugitive emissions from conventional and unconventional fossil resources. Int J Greenhouse Gas Control 33:1-9

Brandão M, Heath GA, Cooper J (2012) What can meta-analyses tell us about the reliability of life cycle assessment for decision support? J Ind Ecol 16:S3-S7

Curran MA, Mann M, Norris G (2005) The international workshop on electricity data for life cycle inventories. J Clean Prod 13:853-862

Dandres T, Gaudreault C, Tirado-Seco P, Samson R (2014) Uncertainty management in a macro life cycle assessment of a 2005-2025 European bioenergy policy. Renew Sustain Energy Rev 36:52-61

Dones R, Ménard M, Gantner U (1998) Choice of electricity-mix for different LCA applications. In: 6th LCA case study symposium SETAC-Europe, 1998. SETAC-Europe, Brussels, pp 1-4

Earles JM, Halog A (2011) Consequential life cycle assessment: a review. Int J Life Cycle Assess $16: 445-453$

Ekvall T, Weidema BP (2004) System boundaries and input data in consequential life cycle inventory analysis. Int J Life Cycle Assess 9:161-171

Frischknecht R, Stucki M (2010) Scope-dependent modelling of electricity supply in life cycle assessments. Int J Life Cycle Assess 15:806-816

Henriksson PJG, Zhang W, Guinée JB (2014) Updated unit process data for coal based energy in China including parameters for overall dispersions. Int J Life Cycle Assess 10:185-195

Hertwich E (2013) Addressing biogenic greenhouse gas emissions from hydropower in LCA. Environ Sci Technol 47:9604-9611

Hertwich E, Gibon T, Bouman EA et al (2015) Integrated life-cycle assessment of electricitysupply scenarios confirms global environmental benefit of low-carbon technologies. Proc Natl Acad Sci 112(20):6277-82. doi: 10.1073/pnas.1312753111

IEA (2014) Electricity information 2014. International Energy Agency/OECD

ISO (2006) ISO 14044 Environmental management - life cycle assessment - requirements and guidelines. Geneva 
Itten R, Frischknecht R, Stucki M (2014) Life cycle inventories of electricity mixes and grid version 1.3. http://www.esu-services.ch/fileadmin/download/publicLCI/itten-2012-electricitymix.pdf. Accessed 24 Feb 2015

Kahrl F, Wang X (2014) Integrating renewables into power systems in China: a technical primer power system operations. Regulatory Assistance Project, Beijing. www.raponline.org/document/download/id/7459. Accessed 24 Feb 2015

Laurent A, Espinosa N (2015) Environmental impacts of electricity generation at global, regional and national scales in 1980-2011: what can we learn for future energy planning? Energy Environ Sci 8:689-701

Lund H, Mathiesen BV, Christensen P, Schmidt JH (2010) Energy system analysis of marginal electricity supply in consequential LCA. Int J Life Cycle Assess 15:260-271

Masanet E, Chang Y, Gopal AR et al (2013) Life-cycle assessment of electric power systems. Annu Rev Environ Resour 38:107-136

Mathiesen BV, Münster M, Fruergaard T (2009) Uncertainties related to the identification of the marginal energy technology in consequential life cycle assessments. J Clean Prod 17:1331-1338

Menten F, Tchung-Ming S, Lorne D, Bouvart F (2015) Lessons from the use of a long-term energy model for consequential life cycle assessment: the BTL case. Renew Sustain Energy Rev 43:942-960

Messagie M, Mertens J, Oliveira L et al (2014) The hourly life cycle carbon footprint of electricity generation in Belgium, bringing a temporal resolution in life cycle assessment. Appl Energy 134:469-476

Miller SA, Keoleian GA (2015) Framework for analyzing transformative technologies in life cycle assessment. Environ Sci Technol 49(5):3067-75 doi:10.1021/es505217a

Moreau V, Bage G, Marcotte D, Samson R (2012) Estimating material and energy flows in life cycle inventory with statistical models. J Ind Ecol 16:399-406

Muller S, Lesage P, Ciroth A et al (2014) The application of the pedigree approach to the distributions foreseen in ecoinvent v3. Int J Life Cycle Assess. doi:10.1007/s11367-014-0759-5

Pehnt M, Oeser M, Swider D (2008) Consequential environmental system analysis of expected offshore wind electricity production in Germany. Energy 33:747-759

Pfenninger S, Hawkes A, Keirstead J (2014) Energy systems modeling for twenty-first century energy challenges. Renew Sustain Energy Rev 33:74-86

Remmen A, Astrup-Jensen A, Frydendal J (2007) Life cycle management. A business guide to sustainability. UNEP. http://www.unep.fr/shared/publications/pdf/DTIx0889xPALifeCycleManagement.pdf. Accessed 24 Feb 2015

Sandén BA, Karlström M (2007) Positive and negative feedback in consequential life-cycle assessment. J Clean Prod 15:1469-1481

Schmidt JH, Thrane M, Merciai S, Dalgaard R (2011) Inventory of country specific electricity in LCA - consequential and attributional scenarios. Methodology report v2. 2.-0 LCA consultants, Aalborg. http://lca-net.com/files/Inventory_of_country_specific_electricity_in_ LCA_Methodology_report_20110909.pdf. Accessed 24 Feb 2015

Soimakallio S, Kiviluoma J, Saikku L (2011) The complexity and challenges of determining GHG (greenhouse gas) emissions from grid electricity consumption and conservation in LCA (life cycle assessment) - a methodological review. Energy 36:6705-6713

Steinmann ZJN, Hauck M, Karuppiah R et al (2014a) A methodology for separating uncertainty and variability in the life cycle greenhouse gas emissions of coal-fueled power generation in the USA. Int J Life Cycle Assess 19:1146-1155

Steinmann ZJN, Venkatesh A, Hauck M et al (2014b) How to address data gaps in life cycle inventories: a case study on estimating $\mathrm{CO}_{2}$ emissions from coal-fired electricity plants on a global scale. Environ Sci Technol 48:5282-5289

Treyer K, Bauer C (2013) Life cycle inventories of electricity generation and power supply in version 3 of the ecoinvent database - part I: electricity generation. Int J Life Cycle Assess, doi: $10.1007 / \mathrm{s} 11367-013-0665-2$ 
Treyer K, Bauer C (2014) Life cycle inventories of electricity generation and power supply in version 3 of the ecoinvent database - part II: electricity markets. Int J Life Cycle Assess, doi: 10.1007/s11367-013-0694-x

Volkart K, Bauer C, Boulet C (2013) Life cycle assessment of carbon capture and storage in power generation and industry in Europe. Int J Greenh Gas Control 16:91-106

Weber CL, Jaramillo P, Marriott J, Samaras C (2010) Life cycle assessment and grid electricity: what do we know and what can we know? Environ Sci Technol 44:1895-1901

Weidema B, Ekvall T, Heijungs R (2009) Guidelines for application of deepened and broadened LCA. ENEA, The Italian National Agency on new Technologies, Energy and the Environment. http://www.leidenuniv.nl/cml/ssp/publications/calcas_report_d18.pdf. Accessed 24 Feb 2015

Yeh S, Rubin ES (2012) A review of uncertainties in technology experience curves. Energy Econ 34:762-771

Yue D, You F, Darling SB (2014) Domestic and overseas manufacturing scenarios of silicon-based photovoltaics: life cycle energy and environmental comparative analysis. Sol Energy 105:669-678

Zamagni A, Guinée J, Heijungs R et al (2012) Lights and shadows in consequential LCA. Int J Life Cycle Assess 17:904-918 